\title{
DEVELOPMENT OF IMPROVED SOLID HOSPITAL WASTE MANAGEMENT PRACTICES IN A NIGERIAN TERTIARY HOSPITAL
}

\author{
O. A. Mokuolu ${ }^{1,}{ }^{*}$, R. S. Akindele ${ }^{2}$ and H. O. Olawumi ${ }^{3}$ \\ 1DEPT. OF WATER RESOURCES AND ENVIRONMENTAL ENGR., UNIVERSITY OF ILORIN ILORIN, KWARA STATE, NIGERIA. \\ 2ENVIRONMENTAL UNIT, UNIVERSITY OF ILORIN TEACHING HOSPITAL, ILORIN, KWARA STATE, NIGERIA. \\ 3 HaEmatology \& Blood TRANSFusion Dept., Univ. OF ILORIN TEACHING HoSPITAL, ILORIN, KWARA STATE, NIGERIA. \\ E-mail addresses:1olubunmimokuolu@yahoo.com²roselinekind@yahoo.com,3toyem66@yahoo.com
}

\begin{abstract}
A pre-intervention situation analysis was conducted to assess Hospital Waste Management (HWM) practices, solutions were proffered for the observed inadequacies and advocacy was made to Hospital administration for which a number of interventional measures were instituted. A post interventional survey was conducted to identify the improvements in HWM and identify areas needing further attention using a structured questionnaire to collect 300 viable samples. Overall outcome includes introduction of HWM plan, establishment of Environmental unit, procurement of waste segregation practices, double chambered incinerator while evaluation of medical and health workers' knowledge and practices showed that 144(48\%) express satisfaction with HWM. The profession of respondents has significant effect on the knowledge about HWM while the educational qualification was not independently associated with level of satisfaction and use of personal protective equipments while handling medical waste at $p=0.05$. It was therefore concluded that continuous training/ capacity development and provision of waste management materials remain essential for consolidating the gains made on HWM.
\end{abstract}

Key words: Hospital, Hospital staff, Nigeria, Waste Management

\section{INTRODUCTION}

Hospital Waste Management (HWM) is an essential part of healthcare delivery. Poorly managed hospital waste exposes healthcare workers, waste handlers, patients, and the community to infections, toxic effects, and injuries and may pollute the environment. In addition, it may create opportunities for collection, resale and potential re-use without sterilization of disposable medical equipment (particularly syringes). This may further compound the burden of disease world-wide especially in a developing country like Nigeria also, inadequate HWM reduces the overall benefits of medical care [1].Hospital Waste Management entails all units of operations involved in managing medical wastes from generation to disposal [2]. Healthcare waste can be categorized as hazardous as it poses potential risk of injury or infection to all those exposed to it, including;(i) Medical staff: doctors, nurses, sanitary staff and hospital maintenance personnel.(ii) In- and out-patients receiving treatment in health-care facilities as well as their visitors.(iii) Workers in support services linked to health-care facilities such as laundries, waste handling and transportation services.(iv)Workers in waste disposal facilities, including scavengers.(v) The general public and especially the children, who play with items scavenged from open waste dumps[3]. Effective management or disposal of hospital waste should include basically; storage in generating premises, effective collection, effective transportation and proper disposal. About $75 \%$ and $90 \%$ of waste produced by health care providers is "non risk" or "general" health-care waste while the remaining 10 $25 \%$ of healthcare waste is regarded as hazardous and may create a variety of health risks [4, 5]. It was reported in 2012 that the average daily waste generated at the study site was $554 \mathrm{~kg} /$ day (202.21tons/year), Average waste generation rate per bed per day was $1.68 \mathrm{~kg} / \mathrm{bed} /$ day, Generation by waste type was $4.5 \%$ pathological, $20 \%$ infectious, $1.6 \%$ were sharps, while $73.9 \%$ were non-infectious or general waste[6]. Following the compilation of the 
findings, advocacy was made to the hospital management on the need to institute urgent measures to address the challenges of health care waste management in the institution. Trainings on HWM were conducted among the medical staff and support staff in 2008, 2009, 2011 and 2013 by master trainers in collaboration with an international non Governmental organization.

Segregation of hospital wastes which is the most important step in the entire process of HWM involves separating different types of waste at the point of generation and keeping them isolated from each other and should be the responsibility of the generator of the waste. There is the need for special attention to be given to the relatively small quantities of infectious and hazardous waste, thereby reducing not only the risks but also the cost of handling, treatment and disposal. The most appropriate way of identifying the categories of health care waste is by sorting the waste into colour-coded plastic bags or containers; World Health Organization (WHO) recommended colour coding for biomedical and healthcare waste are: red for highly infectious waste, yellow for other infectious waste, yellow marked "SHARPS" for sharps waste, brown for pharmaceutical waste, lead box labeled with radioactive symbol for radioactive waste, and black for general or non-infectious waste [4, 5]. $\mathrm{G}^{3}$ uszyñski reported that all medical care facilities in Poland had introduced segregation procedures after UNEP and WHO interventions [7]. Storage of hospital waste in a warm country like Nigeria is 48 hours during cool season while 24 hours is recommended during hot season [5].

On-site transportation of healthcare waste should be done by means of wheeled trolleys, containers or carts that are not used for any other purposes while safe packaging and adequate labeling of waste are essential ingredients for off-site transportation. Treatment methods for Hospital wastes includes: incineration, thermal processes such as autoclaves, microwaves, plasma pyrolysis, and chemical processes in other to render them non- hazardous and then disposed of into air, land or water [8].The paper [3] reported that practical information on HWM is inadequate and research on the public health implications of inadequate management are few and limited in scope.

This longitudinal study revealed the level of improvement in HWM practices, gaps and level of compliance with hospital policy on waste management in a Nigerian tertiary Hospital from 2006 to 2015 through progressive interventions.

\section{METHODOLOGY}

\subsection{Study Area}

The study was conducted at the University of Ilorin Teaching Hospital (UITH),located in Ilorin West Local Government area of Kwara state in the north central region of Nigeria. Ilorin, the capital of Kwara state, Nigeria, located on the latitude $08^{\circ} 29^{\prime}$ and longitude $04^{\circ} 37^{\prime}$. UITH is a 600 bed medical health institution which trains medical students and offers health care services. The Hospital has over a thousand employees which include various professionals like Doctors, Nurses, Laboratory Scientists, Pharmacists, Physiotherapists and Imaging Scientists. Others are: social workers, Nutritionists, Caterers, Accountants, Administrators etc. Services such as security and cleaning are out sourced to private companies. The hospital renders health care services to an average of one thousand patients per day. The methods are grouped into 4 phases:

2.1.1 Phase 1: Observational check list and key informant interview for baseline assessment of the waste management practices of the Hospital were made in 2006. Considering presence or otherwise of HWM plan, availability of segregation materials, storage of hospital waste, off-site and on-site transportation, waste treatment, training of HWM, in addition a physical assessment of the quantity and type of waste was determined. Findings of the observational phase have been reported by [6].

2.1.2 Phase 2: Advocacy to Hospital administration based on observations were made in 2007 to the Hospital management on improved HWM.

2.1.3 Phase 3: Capacity building and trainings of Hospital and support staff on HWM in collaboration with an international organization were conducted were in 2008, 2009, 2011, 2013.

2.1.4 Phase 4: Post interventional survey through the use of structured Questionnaires, Observations and analyzing documents were used. The Questionnaires were designed using closed ended questions. We administered two sets of questionnaires each containing two sections namely the biodata section and the research oriented questions. Respondents selected by quota are; Health workers, Engineers, Administrators, Ward attendants, Cleaners, Waste handlers, incinerator operators, and cleaning Supervisors. The quotas used are; profession and 
educational qualification. The questionnaires were distributed in 2013.

A total of 360 questionnaires were administered to120 patients as part of the community [4, 5], 120 Hospital staff (Medical \& Health care workers, Engineers, and Administrators) and 120 support staff (ward Attendants, Cleaners, waste handlers, Incinerator Operators, and cleaning Supervisors). The Samples were drawn using Quota sampling and simple random sampling techniques. The Quota sampling technique was used to select the category of staff to be included in the study while the Simple random sampling technique was used to select the patients' sample and individual staff from each category that were administered the questionnaires.

The questionnaires were administered personally to respondents in order to minimize error in completion (difficult items on the questionnaire were explained to the respondents). Observations of the hospital's waste management practices from the point of generation to final disposal were made. Quantitative data analysis method was adopted for analyzing the data collected and analysis were carried out using Data Tabulation (Frequency Distribution and percentage) and Chi Square for statistical analysis. The responses were recorded and analyzed with SPSS software.

\section{RESULTS}

The baseline key findings were open dumping, no HWM policy, and no segregation however there was no prolong storage of Hospital waste.

The key interventions were advocacy to Hospital Management, collaboration with international partners for capacity orientation of the Hospital staff, development of Hospital waste management plan, procurement of waste management materials, design and construction of special carte for on-site transportation. The initial successes from these steps facilitated the establishment of an Environmental Unit. Fortuitously, the Hospital became a recipient of $100 \mathrm{~kg} / \mathrm{hr}$ incinerator by the Federal Government. The acquisition of which completed the waste management chain. The ash produced as residue from incineration is dumped at the ash pit to be mixed with other aggregates for production of slabs by the Engineering unit. The data collected in 2006 are presented in tabular form in comparison to the current practices. Table 1 is a summary of changes in key waste management practices during years of study. The Hospital generates mainly Infectious/ highly infectious waste, sharp wastes and general waste. Management structure is as shown in Fig.1.

Table 1: Hospital waste management practices

\begin{tabular}{lll}
\hline Component of HWM & 2006 & 2015 \\
\hline $\begin{array}{l}\text { Waste Segregation } \\
\text { (WHO) standard }\end{array}$ & Not in place & $\begin{array}{l}\text { Practiced by } 60 \% \text { medical } \\
\text { staff }\end{array}$ \\
$\begin{array}{l}\text { Waste treatment/ } \\
\text { disposal }\end{array}$ & Open burning & Incineration \\
$\begin{array}{l}\text { On/ off site } \\
\text { transportation }\end{array}$ & Manual on site & $(1200 \times 600 \times 450) \mathrm{mm}$ Waste \\
$\begin{array}{l}\text { Waste management } \\
\text { plan }\end{array}$ & handling & carte for on-site handling \\
Storage & Less than & In place (fig.1) \\
& 48hous & Less than 48hours \\
\hline
\end{tabular}

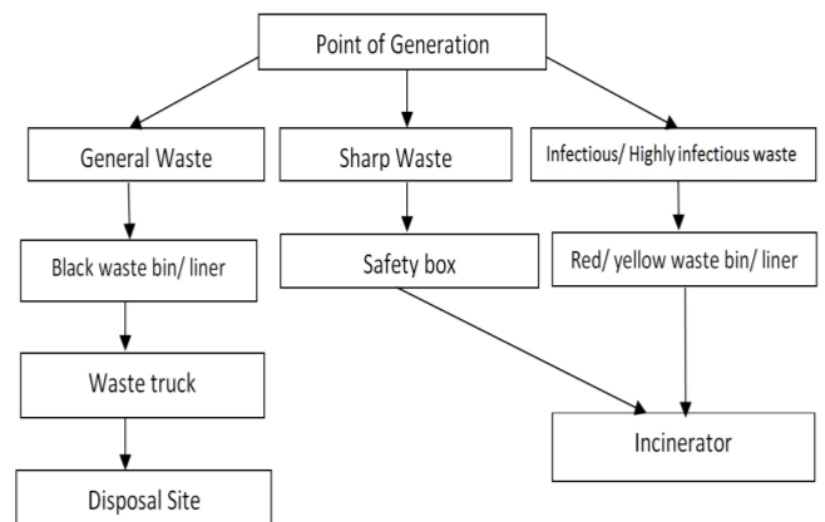

Fig.1: UITH waste management structure

\subsection{Distribution of Questionnaires}

360 Questionnaires were distributed; 120 each for hospital support staff, patients, and hospital staff. 300 were found useful after editing. Table 2 refers to the distribution of respondents who belong to the health profession. The general table shows the profession of respondents. The question of who is responsible for waste disposal in relationship to their professions was tested among the Hospital staff.

Table 3 shows that a higher percentage of respondents who are in the medical field have a better understanding of their role in hospital waste management while their counterparts in the other profession are less aware of their responsibilities in ensuring proper hospital waste management.

$\mathrm{H}_{0}$ : Profession has no significant effect on the respondents' knowledge about who is responsible to disposal of medical waste

$\mathrm{H}_{1}$ : Profession has significant effect on the respondents' knowledge about who is responsible to disposal of medical waste 
Decision Rule: Accept $\mathrm{H}_{\mathrm{o}}$ if $\chi^{2}$ cal. is greater than $(>) \chi^{2}$ 0.05: Reject $\mathrm{H}_{\mathrm{o}}$ and accept the alternative Hypothesis $\left(\mathrm{H}_{1}\right)$ if the $\chi^{2}$ cal. is less than $(<) \chi^{2} 0.05$

Table 3: The relationship between the professions of respondents (Hospital Staff) and their knowledge about who is responsible to disposal of medical waste.

Comment: Since $\chi^{2}$ cal. (0.001) $<\chi^{2} 0.05$, we reject null-hypothesis $\left(\mathrm{H}_{\mathrm{o}}\right)$ and accept $\mathrm{H}_{1}$ thus, conclude that the profession of respondents has significant effect on their knowledge about who is responsible to disposal of medical waste.

All the Respondents were tested on their satisfaction with HWM practices. Table 5 shows the response of all respondents to the question; are you satisfied with the hospital's waste management practices?

Table 2: Professions of Respondents

\begin{tabular}{lllll}
\hline Professions & Patients & Hospital Staff & Total & Percentage \\
\hline Health Workers & 18 & 70 & 88 & $44 \%$ \\
Engineering & 14 & 7 & 21 & $10.5 \%$ \\
Administration & 38 & 23 & 61 & $30.5 \%$ \\
Others & 30 & 0 & 30 & $15 \%$ \\
Total & 100 & 100 & 200 & $100 \%$ \\
\hline & Support Staff & Percentage & \\
Ward Attendants & 25 & $25 \%$ & & \\
Cleaners & 53 & $53 \%$ & & \\
Waste handlers & 9 & $9 \%$ & & \\
Incinerator Operators & 3 & $3 \%$ & \\
Cleaning Supervisors & 10 & $10 \%$ & \\
Total & 100 & $100 \%$ & & \\
\cline { 1 - 2 }
\end{tabular}

Table 3: The relationship between the professionals of respondents (Hospital staff) and their knowledge about who is responsible to disposal of medical waste

\begin{tabular}{|c|c|c|c|c|c|c|c|}
\hline \multirow[b]{2}{*}{ Profession } & & & \multicolumn{4}{|c|}{ Medical waste disposal is the responsibility of } & \multirow{2}{*}{ Total } \\
\hline & & & Cleaners & Environmental Unit & Management & Everyone & \\
\hline & \multirow{2}{*}{ Health Workers } & Count & 4 & 13 & 2 & 51 & 70 \\
\hline & & Expected Count & 6.3 & 19.6 & 2.1 & 42.0 & 70.0 \\
\hline & \multirow{2}{*}{ Engineering } & Count & 0 & 3 & 1 & 3 & 7 \\
\hline & & Expected Count & 0.6 & 2.0 & 0.2 & 4.2 & 7.0 \\
\hline & \multirow{2}{*}{ Administration } & Count & 5 & 12 & 0 & 6 & 23 \\
\hline & & Expected Count & 2.1 & 6.4 & 0.7 & 13.8 & 23.0 \\
\hline \multirow{2}{*}{ Total } & & Count & 9 & 28 & 3 & 60 & 100 \\
\hline & & Expected Count & 9.0 & 28.0 & 3.0 & 60.0 & 100.0 \\
\hline
\end{tabular}

Table 4: Chi-Square Tests

\begin{tabular}{l|c|c|c}
\hline & Value & Df & Asymp. Sig. (2-sided) \\
\hline Pearson Chi-Square & $23.538^{\mathrm{a}}$ & 6 & .001 \\
Likelihood Ratio & 22.717 & 6 & .001 \\
Linear-by-Linear Association & 17.777 & 1 & .000 \\
Number of Valid Cases & 100 & & \\
\hline
\end{tabular}

Table 5: Satisfaction with Hospital waste management by respondents

\begin{tabular}{cccccc}
\hline Response & Support staff & Patients & Hospital staff & Frequency & Percentage \\
\hline Yes & 40 & 64 & 40 & 144 & $48 \%$ \\
No & 60 & 36 & 60 & 156 & $52 \%$ \\
Total & 100 & 100 & 100 & 300 & $100 \%$ \\
\hline
\end{tabular}


Table 6: The relationship between the educational qualification of respondents (hospital support staff) and their use of personal protective equipment (PPE)

\begin{tabular}{|c|c|c|c|c|}
\hline \multirow{2}{*}{\multicolumn{2}{|c|}{$\begin{array}{l}\text { Educational } \\
\text { Qualification }\end{array}$}} & \multicolumn{2}{|c|}{$\begin{array}{l}\text { Medical waste can be } \\
\text { handled without the use of } \\
\text { personal protective } \\
\text { equipment like gloves and } \\
\text { masks }\end{array}$} & \multirow[t]{2}{*}{ Total } \\
\hline & & Yes & No & \\
\hline \multirow[b]{2}{*}{ Graduate } & Count & 8 & 0 & 8 \\
\hline & $\begin{array}{l}\text { Expected } \\
\text { Count }\end{array}$ & 7.1 & .9 & 8.0 \\
\hline \multirow{2}{*}{ OND/NCE } & Count & 20 & 0 & 20 \\
\hline & $\begin{array}{l}\text { Expected } \\
\text { Count }\end{array}$ & 17.8 & 2.2 & 20.0 \\
\hline \multirow{2}{*}{ Secondary } & Count & 39 & 10 & 49 \\
\hline & $\begin{array}{l}\text { Expected } \\
\text { Count }\end{array}$ & 43.6 & 5.4 & 49.0 \\
\hline \multirow[b]{2}{*}{ Primary } & Count & 19 & 1 & 20 \\
\hline & $\begin{array}{l}\text { Expected } \\
\text { Count }\end{array}$ & 17.8 & 2.2 & 20.0 \\
\hline \multirow[t]{2}{*}{ None } & Count & 3 & 0 & 3 \\
\hline & $\begin{array}{l}\text { Expected } \\
\text { Count }\end{array}$ & .2 .7 & 3 & 3.0 \\
\hline \multirow[t]{2}{*}{ Total } & Count & 89 & 11 & 100 \\
\hline & $\begin{array}{l}\text { Expected } \\
\text { Count }\end{array}$ & 89.0 & 11.0 & 100.0 \\
\hline
\end{tabular}

Table 7: Chi-Square Tests

\begin{tabular}{l|c|c|c}
\hline & Value & Df & $\begin{array}{c}\text { Asymp. Sig. } \\
\text { (2-sided) }\end{array}$ \\
\hline Pearson Chi-Square & $8.997^{\mathrm{a}}$ & 4 & .061 \\
Likelihood Ratio & 11.774 & 4 & .019 \\
Linear-by-Linear & .537 & 1 & .464 \\
Association & 100 & & \\
N of Valid Cases & & \\
\hline
\end{tabular}

Table 8: waste segregation practice by Medical and Health Workers

\begin{tabular}{lll}
\hline Responses & Frequency & Percentage \\
\hline Correct & 42 & 60 \\
Wrong & 28 & 40 \\
Total & 70 & $100 \%$ \\
\hline
\end{tabular}

The response shows that that $52 \%$ of the respondents are dissatisfied with current waste management practice for reasons varying from poor segregation practice to inadequate segregation materials like the colour coded bins and liners.

The uses of Personal Protective Equipments (PPE) were tested on the support staff. Table 6 shows that $89 \%$ of the support staff are of the opinion that medical waste can be handled without the use of PPE and the Chi square test analysis shows that educational qualification of the respondents has no significant effect on their opinion. This contravenes the training that may have been conducted in the past. $\mathrm{H}_{\mathrm{o}}$ : Educational qualification has no significant effect on the respondents' use of PPE while handling medical waste.

$\mathrm{H}_{1}$ : Educational qualification has significant effect on the respondents' use of PPE while handling medical waste

Decision Rule: Accept $\mathrm{H}_{0}$ if $\chi^{2}$ cal. is greater than $(>) \chi^{2}$ 0.05: Reject $\mathrm{H}_{\mathrm{o}}$ and accept the alternative Hypothesis $\left(\mathrm{H}_{1}\right)$ if the $\chi^{2}$ cal. is less than $(<) \chi^{2} 0.05$

Comment: Since $\chi^{2}$ cal. (0.061) $>\chi^{2} 0.05$, we accept null-hypothesis $\left(\mathrm{H}_{0}\right)$ and conclude that the educational qualification of respondents has no significant effect on their use of PPE while handling medical waste.

Waste segregation (separation) is an important process in HWM. Hospital's health workers who are main generators of these categories of waste were tested on this. Table 8 shows the response of the hospital's health workers to the Question- Medical Waste should be segregated at the point of generation by who?

Of the 70 respondents $42(60 \%)$ are aware of their responsibly to separate waste into the colour coded bins provided at the point of generation while the remaining $40 \%$ are yet to comply with segregation; $24(34.3 \%)$ believed it is the duty of waste handlers, while $4(5.7 \%)$ believed it is the duty of the cleaners. This reveals a need for training and retraining of staff to ensure total compliance and effective waste management practice.

\section{DISCUSSION}

Hospital waste management in the study area has shown a significant improvement in practice over the period of study. The Hospital had no HWM plan at the onset of the study in 2006, However, it currently has a waste management structure in place as shown in Fig.1.Waste segregation, a critical step to achieve waste minimization, cost reduction and sustainable 
waste management practice is being practice by $42(60 \%)$ of medical and healthcare respondents. This result is higher than $31.9 \%$ of healthcare providers that segregated waste by their type with the available dust bins in healthcare facilities of Gondar town, Northwest Ethiopia [9] bringing the need for more awareness and training/ retraining of hospital staff. In a similar study by[3], training in Hospital waste management among staff surveyed was $11 \%, 46 \%$ understood the importance of Hospital waste management in the provision of safety to the public while level of waste practice was found to be zero (unsustainable).[7] in his finding recommended training of health care administrators, medical staff and workers as an important component of National planning for health care waste management in Poland. A similar study conducted by[9] in Gondar town, Northwest Ethiopia, indicated that those who took training on healthcare waste management were 2.29 times more likely to apply healthcare waste management practice than their counterparts. Many literatures indicated that regular training of HCWs on healthcare waste management had a great role on practices of healthcare waste management $[9,4,10]$.

The result showed that a higher percentage of respondents who are in the medical field have a better understanding of their role in hospital waste management while their counterparts in the other profession are less aware of their responsibilities in ensuring proper hospital waste management. This is similar to the report by [9] conducted in Ethiopia that those who had higher knowledge on diseases transmission with healthcare waste were 5.19 times more likely to practice healthcare waste management and moderate knowledge were 2.48 times more than health care workers who had low knowledge about diseases transmission through improper healthcare waste management. Result from the study showed $89 \%$ of the support staff are of the opinion that medical waste can be handled without the use of PPE and the Chi square test analysis shows that educational qualification of the respondents has no significant effect on their opinion. This contravenes the training that may have been conducted in the past. The result also showed that 156(52\%) of the respondents are dissatisfied with current waste management practice for reasons varying from poor segregation practice to inadequate segregation materials like the colour coded bins and liners. This is in line with many findings in developing countries on healthcare wastes management revealing that segregation, collection of waste using recommended color coding container and storage of waste in isolated area were not satisfactory $[11,3,12,13,14]$. A double chambered $100 \mathrm{Kg} / \mathrm{hr}$ incinerator has been provided as a means of waste treatment/ disposal whereas this was not so before intervention as open burning was the usual practice. Five percent of hospitals visited in Ibadan practice open dumping without regard for scavengers that pick from such dumpsites possibly for resale [14] as was observed in the study area before intervention. There is near-total absence of institutional arrangements for the management of Hospital waste and currently there are no regulations, legislation or special edicts on medical waste management in the country.

\section{CONCLUSION AND RECOMMENDATIONS}

Wastes emanating from healthcare activities can have adverse effects. Some types of healthcare waste represent a higher risk to health; these include infectious wastes and sharps.

The overall outcome of this interventional study is that there is significant improvement in HWM in terms of awareness of its danger if not well managed, establishment of HWM plan, procurement of waste management materials, training of both medical and non medical staff, However 156 (52\%) of the respondents are dissatisfied with current waste management practice for reasons varying from poor segregation practice to inadequate segregation materials like the colour coded bins and liners making room for further training and logistics for improvement.

The following are the recommendations:

1) More awareness of Hospital policy on HWM to staff through training and retraining should be created.

2) Waste segregation through provision of segregation materials and follow up on same should be encouraged.

3) Advocacy on hazards associated with mismanagement of medical waste to the community through the media should be carried out.

\section{REFERENCES}

[1] SBC/UNEP/WHO/FMOH Proceedings on "Inventory of Health-care waste in Nigeria" organized by the Secretariat of the Basel Convention of the United Nations Environment Program (SBC/UNEP) and the World Health Organization (WHO) in collaboration 
with the Federal Ministry of Environment, Nigeria. 2002.

[2] Health Care Without Harm (HCWH) Nonincineration medical waste treatment technologies. A resource for Hospital Administration, Facility Managers, Health Care Professionals, Environmental Advocates, and Community Members. 2001. HCWH 1755 S Street, N.W Suite 6B, Washington, DC 20009. www.noharm.org.

[3] Abah Stephen Obekpa and Ohimain Elijah Ige, Healthcare waste management in Nigeria: A case study. Journal of Public Health and Epidemiology vol3 (3), pp 99-110, 2011.

[4] WHO, 2013. Safe management of waste from healthcare activities (second version)http://www.healthcare-waste.org/

(Accessed August 12 th 2015)

[5] Pruss, A., Giroult, E and Rush Brook, D. Safe management of waste from health care activities. Geneva: World Health Organization, 1999.

[6] Mokuolu, O. A., Olawumi, H. O., Sule, B. F. Generation and composition of medical waste in a University Teaching Hospital. Proceedings of Civil 2012 @ UNILORIN $4^{\text {th }}$ Annual \& $2^{\text {nd }}$ International Conference of Civil Engineering. pp 152-156, 2012.

[7] $G^{3}$ uszyñski Pawe ${ }^{3}$,. Information on the management of medical waste in Poland. Waste Prevention Association 3R.Nursing, Health And The Environment Conference, 1999
[8] Yadav, M. Hospital waste- a major problem. Hospitals today, J.K. Practitioner; 8 (4)pp 276 - 282, 2001.

[9] Muluken Azage, Haimanot Gebrehiwot, and Mesafint Molla,. Healthcare waste management practices among healthcare workers in healthcare facilities of Gondar town, Northwest Ethiopia, Health Science Journal Volume 7 Issue 3, 2013.

[10] Sridhar, M. K. C., Wahab, W. B., Agboola, S. B., Badiane, A.. Health Care Wastes Management. Ibadan University Press., 2009.

[11] Williams George Louis, Medical Waste Disposal Practices in some Hospitals and Clinical Laboratories in the Accra Metropolis (Ghana). Journal of Civil and Environmental Research Vol 3, No.11, 2013.

[12] Coker, A., Sangodoy in, A., Sridhar, M.K., Booth, C. Olomolaiye, P., and Hammond, F., Medical Waste Management in Ibadan, Nigeria: Obstacles and Prospects", Waste Management, Volume 29, issue 2, pp 804-811, 2009.

[13] Bassey B. E., Benka-Coker M.O, and Aluyi H. S. A, Characterization and management of solid medical wastes in the FCT, Abuja Nigeria. African Health Sciences; 6(1); pp 58-63, 2006

[14] Coker, A. O, Sangodoy in, A. Y. and Ogunlowo O. O. Managing Hospital Wastes in Nigeria. Proceedings of $24^{\text {th }}$ WEDC Conference, Islamabad, Pakistan. pp 7072. 1998 